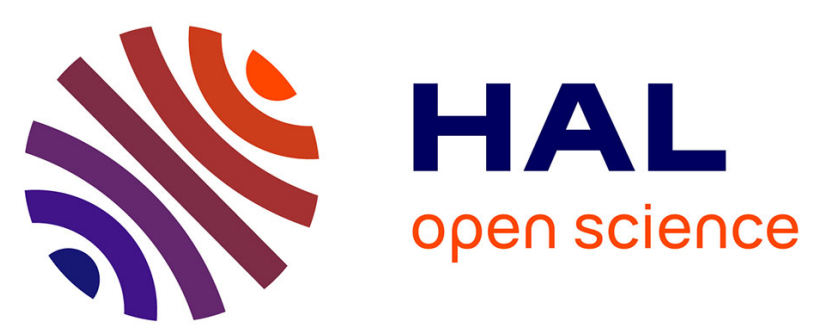

\title{
Recovering heat from hot drain water-Experimental evaluation, parametric analysis and new calculation procedure
}

\author{
Mohamad Ramadan, Thierry Lemenand, Mahmoud Khaled
}

\section{To cite this version:}

Mohamad Ramadan, Thierry Lemenand, Mahmoud Khaled. Recovering heat from hot drain waterExperimental evaluation, parametric analysis and new calculation procedure. Energy and Buildings, 2016, 128, pp.575-582. 10.1016/j.enbuild.2016.07.017 . hal-02525529

HAL Id: hal-02525529

https://univ-angers.hal.science/hal-02525529

Submitted on 31 Mar 2020

HAL is a multi-disciplinary open access archive for the deposit and dissemination of scientific research documents, whether they are published or not. The documents may come from teaching and research institutions in France or abroad, or from public or private research centers.
L'archive ouverte pluridisciplinaire HAL, est destinée au dépôt et à la diffusion de documents scientifiques de niveau recherche, publiés ou non, émanant des établissements d'enseignement et de recherche français ou étrangers, des laboratoires publics ou privés. 


\title{
Recovering heat from hot drain water-Experimental evaluation, parametric analysis and new calculation procedure
}

\author{
Mohamad Ramadan ${ }^{\mathrm{a}, *}$, Thierry lemenand ${ }^{\mathrm{b}}$, Mahmoud Khaled ${ }^{\mathrm{a}, \mathrm{c}}$ \\ a Energy and Thermo-Fluid Group, School of Engineering, Lebanese International University LIU, P.O. Box 146404, Beirut, Lebanon \\ ${ }^{\mathrm{b}}$ LARIS EA 7315, ISTIA, University of Angers, Angers, France \\ ' Univ Paris Diderot, Sorbonne Paris Cité, Interdisciplinary Energy Research Institute (PIERI), Paris, France
}

\section{A R T I C L E I N F O}

\section{Article history:}

Received 8 February 2016

Received in revised form 26 May 2016

Accepted 6 July 2016

Available online 6 July 2016

\section{Keywords:}

Heat recovery

Energy management

Drain water

Prototype

Heat transfer

Calculation procedure

\begin{abstract}
A B S T R A C T
In the last decade, a tremendous effort has been made to find solutions permitting to decrease the consumption of fossil energy. Energy recovery is one of the emerging solutions. It consists in recuperating the waste energy that exists in many systems and reutilizing it in a useful way. Heat recovery from hot water drain is one of energy recovery systems that is taking its reputation nowadays due to the major part of the electric bill occupied by heating domestic water. This paper reports a calculation procedure that can be applied to many drain heat recovery systems. It can be utilized as a pre-calculation tool to evaluate and analyze drain heat recovery systems or as an optimization technique to enhance an existing system. To proceed, a generic experimental setup is devised and a parametric experimental analysis is performed using the developed setup. Experiments have shown that the system can considerably increase the temperature of the cold supply water for some configurations. Based on experimental results, many drain systems can be preliminary evaluated and analyzed using a new suggested systematic calculation procedure based on experimentally determined parameters.
\end{abstract}

(C) 2016 Elsevier B.V. All rights reserved.

\section{Introduction}

The high demand on energy is tremendously increasing due to three main reasons that are the expansion of the industrial domain, the depletion of the fuel resource and the rapid population growth. Huge efforts are being made to overcome this severe crisis. Solutions can be classified into three categories:

Using renewable energy resources such as wind energy [1,2], solar energy [3,4] and geothermal energy [5,6].

Improving energy management $[7,8]$ which consists in organizing energy resources so that the loss of energy is minimized and the use of energy is optimized.

Developing energy recovery $[9,10]$ which consists in recovering the lost heat in energy systems and using it in other applications.

Indeed energy recovery may take several forms. The most developed one is heat recovery [11-13] where the recovered energy is heat. In other terms, the lost heat of a system can be re-used as heat source for another application. Heat recovery studies cover wide range of energy domains. Industrial applications are sources of

\footnotetext{
* Corresponding author.

E-mail addresses: dr.ramadan.mohamad@gmail.com, mahmoud_khaled21@hotmail.com (M. Ramadan).
}

huge heat loss that explain why many works have investigated heat recovery from industrial machines [14]. Heat recovery from internal combustion engines [15] has also been studied. Other works concern heat recovery in building applications [16-18]. Heating water in residential building represents the higher contribution in the total amount of energy consumption. On the other hand, drain water is a rich source of heat loss that can be recovered.

In one of the first works on heat recovery from drain water [19], the consumption of energy for water heating is studied in terms of the life-style of occupants. Authors showed that an energy saving up to $10 \%$ can be obtained in some configurations. In another work [20], study of recovering heat from waste water in dyeing process is presented and energy saving is reported by the authors. Heat recovery from dish washers is investigated in [21]. The authors presented an experimental study and showed that the system is economically beneficial. Recovering waste heat from systems using hot water such as sauna, to be used in a heat pump as heat source is studied and analyzed in [22]. Waste heat recovery from drain water in high rise building is investigated in [23]: a horizontal counter flow heat exchanger is utilized to extract heat and use it to heat cold water. Authors show that by installing heat recovery system up to $15 \%$ of the waste water heat can be recovered. Enhancing heat pump used in public shower facilities using heat recovery system and solar system is studied in [24]. Before heating water by a heat 


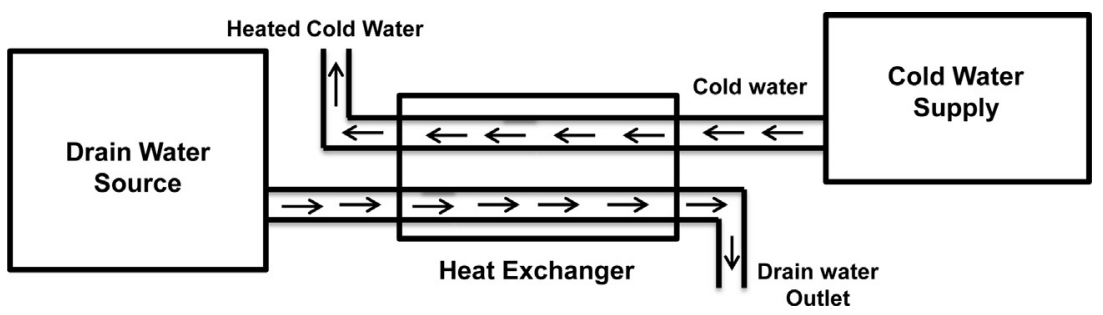

Fig. 1. Drain water heat recovery system (DWHRS) working principle.

pump, it is heated by solar system then by mean of heat recovery system. It is mentioned that using such a system reduces the energy consumption as well as the pollution level and it has lower operating cost. Heat recovery from horizontal drain is investigated in [25]. Authors mention that using horizontal heat recovery system is applicable and can be efficient; its efficiency depends on several factors. It is reported that the utilization of such a system reduce highly the emission of carbon dioxide. Benntjes et al. [26] showed that the effectiveness of heat recovery system deceases with the flow rate and that there is a critical flow rate below which the performance cannot be extrapolated. In [27], a study on vertical heat recovery system with heat pump shows that the contact resistance between the copper pipes and the heat resistance on the inside of the drain water has the higher contribution to the heat resistance. It has been shown that using such a heat pump, $25 \%$ of the heat can be recovered. A financial study on the utilization of drain water heat recovery system is presented in [28]. Authors presented a model allowing estimating the financial efficiency of the system. The study covers several heat recovery configurations and different installation parameters. Utilization of sewer water as heat source is studied in $[29,30]$ and a case study concerning the city of Bologna (Italy) is considered. Monitoring data are used to obtain a correlation between the waste water flow rate and its temperature. Parametric study on drain water heat recovery using inline vertical heat exchanger for several flow scenarios is performed in [31]: the authors showed that the amount of recovered heat highly depends on the sizing of the heat recovery system. Heat recovery from waste water of therapy systems in spa is presented in [32]. The effect of the angle of the heat recovery system with respect to the vertical is studied in [33]: authors showed that the effectiveness decreases when the angle with respect to the vertical increases.

The works cited above cover a wide range of applications related to drain heat recovery. Each study presents an analysis focused on a specific parameter. However, none of these studies presents a general approach that can be used as a reference for drain heat recovery calculation. That is why it is essential to propose a generalized procedure of study for drain heat recovery system that can be adopted independently from the configuration, the application and the system parameters. In this context, this paper presents a calculation procedure that may be applied to generally many drain heat recovery systems providing that some preliminary tests are done for the drain system considered and for corresponding real scenarios. It can be utilized as a pre-calculation tool to evaluate drain heat recovery systems or as an optimization technique to enhance an existing system.

The originality of the present work resides in the generic experimental setup developed and the analysis performed based on the obtained results. Moreover, the experimental analysis was performed in such a way that has permit to suggest a new systematic calculation procedure in order to evaluate and analyze drain heat recovery systems based on preliminary experimental tests.

The remaining of this paper is composed of four parts. Part two is dedicated to present the experimental approach. In part three, results are discussed. New calculation procedure is presented in part four and finally part five is reserved to the conclusions.

\section{Materials and methods}

In this section, the principle of the heat recovery concept (Section 2.1), the prototype implemented (Section 2.2), and the experimental setup (Section 2.3) are presented.

\subsection{Principle}

The principle of the drain water heat recovery system (DWHRS) consists in heating/preheating the supply water before it enters the water heater, by the heat contained in the drain water. Indeed, the water temperature after any drainage type is relatively high. In other terms the drain water temperature is clearly higher than the water supply temperature which may be below $5^{\circ} \mathrm{C}$ in cold regions. From a heat transfer point of view, this temperature difference between the drain water and the supply water may be transformed to a heat rate that can heat the supply water. The DWHRS (Fig. 1) can be viewed as a heat exchanger, in which the hot fluid is the drain water and the cold fluid is the supply water. Several types of (DWHRS) can be obtained according to the heat exchanger type which is the heart of the system. The most commonly used heat exchangers are the coiled and concentric tube heat exchangers that are used in this study.

\subsection{Prototype}

To study the heat recovery from drainage system and analyze its performance, a prototype is constructed, as shown schematically in Fig. 2.

The prototype is composed of five main parts: water supply tank, water pump, drain box, electric heater, and coiled heat exchanger. The water supply tank is a plastic tank of $60 \mathrm{~L}$ volume, utilized to supply the system. The water pump insures the necessary water pressure so that water flows in the system. A control valve is used

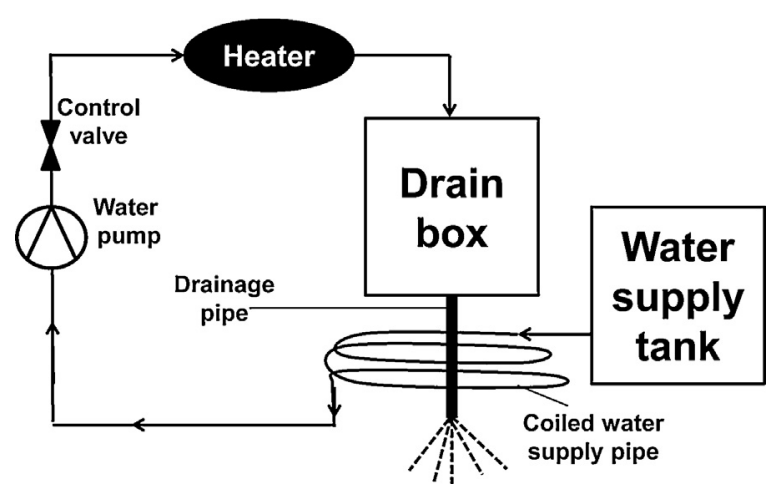

Fig. 2. Schematic of the constructed prototype. 


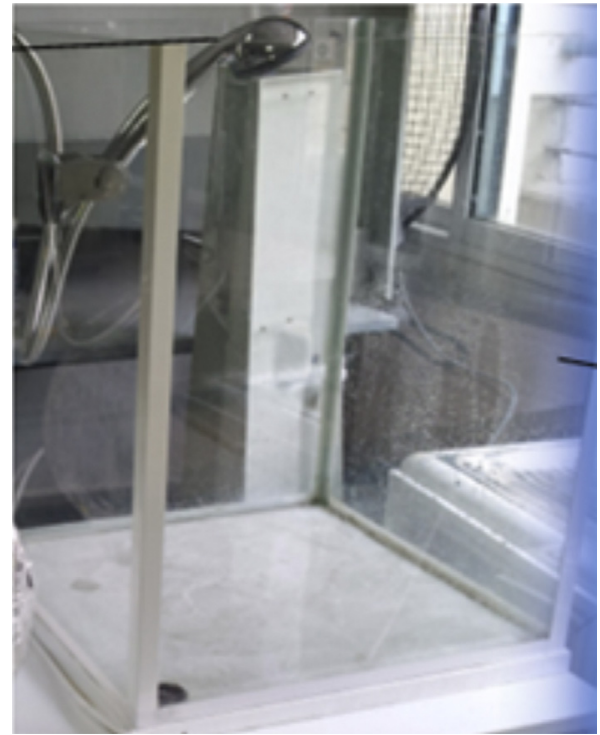

Fig. 3. Glass box simulating the drainage type region.

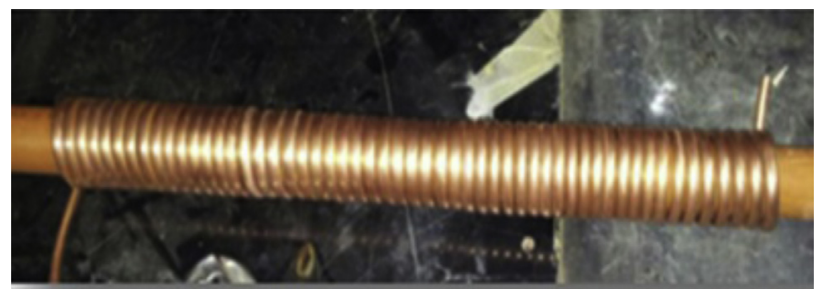

Fig. 4. Coiled heat exchanger used in the recovery system.

directly downstream of the pump in order to control a prescribed flow rate in the circuit.

The drain box represents the region of a given type of drainage carrying the hot water before its drainage. As illustration, this box can be a shower chamber, a sink, a dish washer, a washing machine, etc. It consists of a glass box (Fig. 3 ) of $3 \mathrm{~mm}$ thickness fixed by aluminum rods at its corners. It has a length and width of $40 \mathrm{~cm}$, a height of $60 \mathrm{~cm}$ and a total surface area of $1.28 \mathrm{~m}^{2}$.

An insulated boiler of $50 \mathrm{~L}$ size is used to heat the water after passing through the heat exchanger tube. The coiled heat exchanger is constructed using a single copper coil of $12.7 \mathrm{~mm}$ inner diameter and $0.6 \mathrm{~mm}$ thickness wrapped around a circular copper pipe of $41.3 \mathrm{~mm}$ inner diameter, $1.2 \mathrm{~mm}$ thickness and a $70 \mathrm{~cm}$ length, as shown in Fig. 4. The circular copper pipe serves as drainage pipe and is connected directly to the drainage box base. Fiber glass insulation of $37.5 \mathrm{~mm}$ thickness is utilized to reduce heat losses.

\subsection{Experimental setup}

In order to test the thermal performance of the system, measurements of temperatures and flow rates are required. Four K-type thermocouples are used to measure temperatures $T_{c, i}$ and $T_{c, o}$ at respectively the inlet and outlet of the coiled supply pipe (cold side of the exchanger) and $T_{h, i}$ and $T_{h, o}$ at respectively the inlet and outlet of the drainage pipe (hot side of the exchanger).

Water flow rates are measured using the stopwatch method to fill a given tank volume. The mass flow rate is then calculated according to the following relation:

$\dot{m}=\rho \frac{V}{t}$ where $\rho$ is the water density, $V$ the filled volume and $t$ the time required to fill the volume $V$. When the different temperatures and flow rates are measured for a given tested configuration, different performance parameters of the recovery system can be calculated. The recovered heat can be calculated from the following relation:

$\dot{Q}_{R}=\dot{m}_{c} C_{p, c}\left(T_{c, o}-T_{c, i}\right)$

where $\dot{m}_{c}$ and $C_{p, c}$ are respectively the mass flow rate and specific heat of the cold water (water from the supply tank).

The efficiency $\eta$ of the recovery system, which represents the ability of the system to avoid wasting energy, is defined as the ratio of the heat recovered by the cold water over the heat lost by the hot water:

$\eta=\frac{\dot{Q}_{R}}{\dot{m}_{h} C_{p, h}\left(T_{h, i}-T_{h, o}\right)}$

where $\dot{m}_{h}$ and $C_{p, h}$ are respectively the mass flow rate and specific heat of the hot water (water from the drain).

The effectiveness $\varepsilon$ of the system which represents a measurement of the performance of the heat exchanger when using the NTU method [34] is defined as the ratio of the heat recovered by the cold water over the maximum possible heat transfer that can be hypothetically achieved in a counter-flow heat exchanger of infinite length, calculated from the following relation:

$\varepsilon=\frac{\dot{Q}_{R}}{\dot{m}_{h} C_{p, h}\left(T_{h, i}-T_{c, i}\right)}$

In Eq. (4), the hot side is considered in the ideal case since the mass flow rate in the hot side is expected to be lower than in the cold side due to water losses due to wall adhesion in the drainage box.

Three sets of experiments are carried out. The first set of experiments corresponds to different inlet cold temperatures (water supply tank) varying from $3.2{ }^{\circ} \mathrm{C}$ to $22.4^{\circ} \mathrm{C}$ with a fixed hot inlet temperature of $70^{\circ} \mathrm{C}$ and a cold flow rate of $0.146 \mathrm{~kg} / \mathrm{s}$ (the hot flow rate is specified further in the paper). The different cold temperatures are obtained by initiating a temperature of $3.2^{\circ} \mathrm{C}$ by adding ices to the cold supply tank and performing successive measurements when ices melt.

The second set of experiments is performed for different cold water flow rates (which implies different values of hot flow rates) varying from $0.058 \mathrm{~kg} / \mathrm{s}$ to $0.146 \mathrm{~kg} / \mathrm{s}$.

The third set is carried out for different hot inlet temperatures varying from $40^{\circ} \mathrm{C}$ to $80^{\circ} \mathrm{C}$. The cold inlet temperature is recorded for each configuration of set two and three and ranges from $25^{\circ} \mathrm{C}$ to $40^{\circ} \mathrm{C}$.

\section{Results and analysis}

In this section, the different results obtained as well as the corresponding observations and analysis will be presented. Fig. 5 shows the variation of the hot water flow rate (hot water to fall in the drainage) in function of the cold water flow rate (water from the water supply tank).

From Fig. 5a, it can be noticed that the hot flow rate is lower than the cold flow rate. As illustration for a cold flow rate of $0.146 \mathrm{~kg} / \mathrm{s}$, the hot flow rate is $0.122 \mathrm{~kg} / \mathrm{s}$. This means that $0.024 \mathrm{~kg} / \mathrm{s}$ are lost in the drain box due to adhesion of water on the inner walls. The percentage of hot water to the cold water flow rate (Fig. 5b) is almost around $81 \%-85 \%$. It should be noticed that given the percentage of hot flow rate to cold flow rate, a considerable time was taken between two consecutive tests in order to have sufficient drying of the inner wall of the drain box.

Fig. 6 shows the variation of the heat recovered in the system in function of the cold inlet temperature (Eq. (2)). It is shown that the 


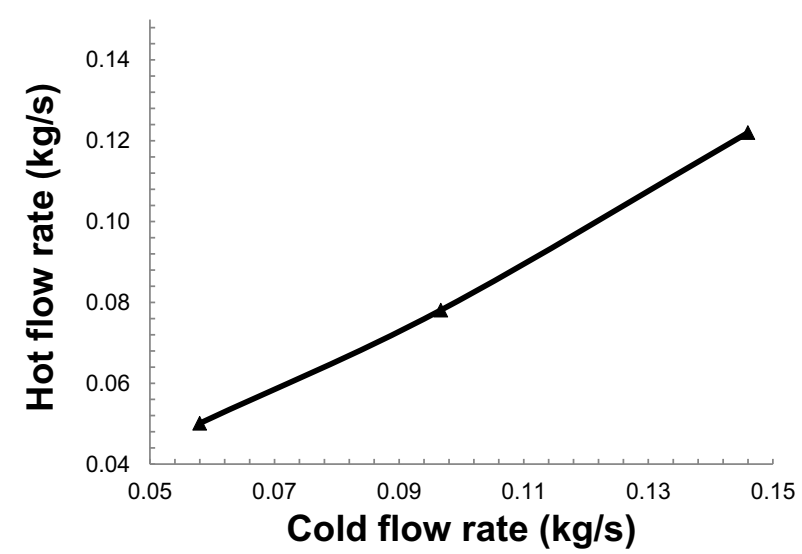

(a)

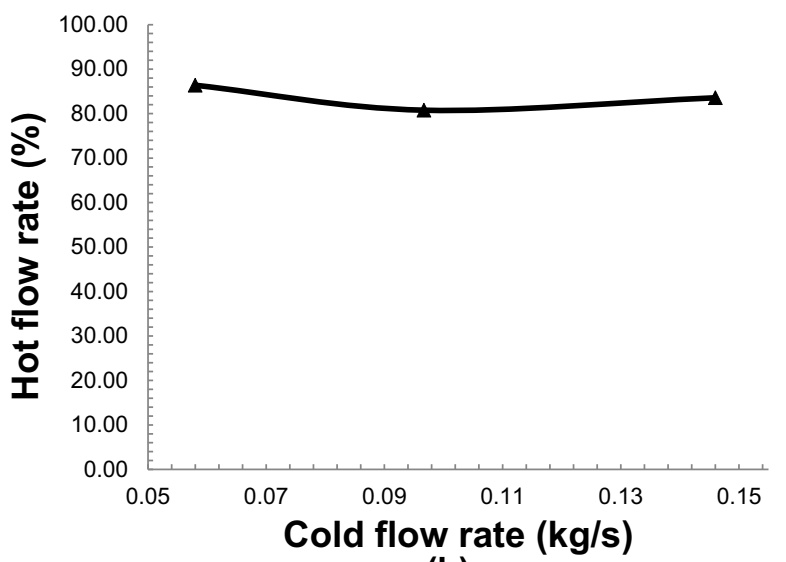

(b)

Fig. 5. Variation of (a) hot water flow rate and (b) percentage of hot water flow rate in terms of the cold water flow rate.

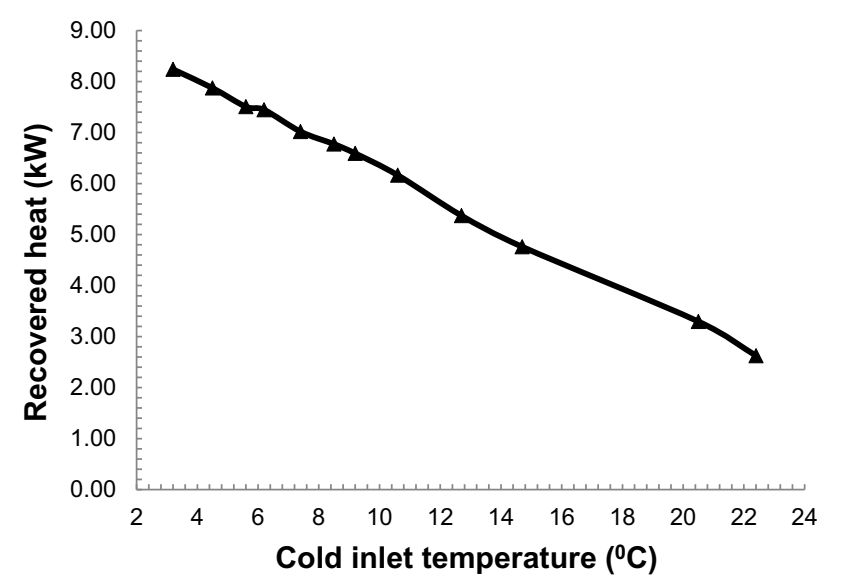

Fig. 6. Heat recovered in function of the cold inlet temperature.

heat recovered decreases quasi-linearly as the cold inlet temperature increases. As illustration, the heat recovered decreases from $8.24 \mathrm{~kW}$ to $2.62 \mathrm{~kW}$ when the cold inlet temperature increases from $3.2^{\circ} \mathrm{C}$ to $22.4^{\circ} \mathrm{C}$.

To investigate deeper the performance of the system in relation with the cold temperature, the efficiency and effectiveness (Eqs. (2)-(4)) are plotted in Fig. 7. It can be shown that when the cold inlet temperature increases, the efficiency and the effectiveness decrease almost linearly. As illustration when the cold inlet temperature increases from $3.2^{\circ} \mathrm{C}$ to $22.4^{\circ} \mathrm{C}$, the efficiency decreases from around $100 \%$ to $47 \%$ and the effectiveness decreases from around

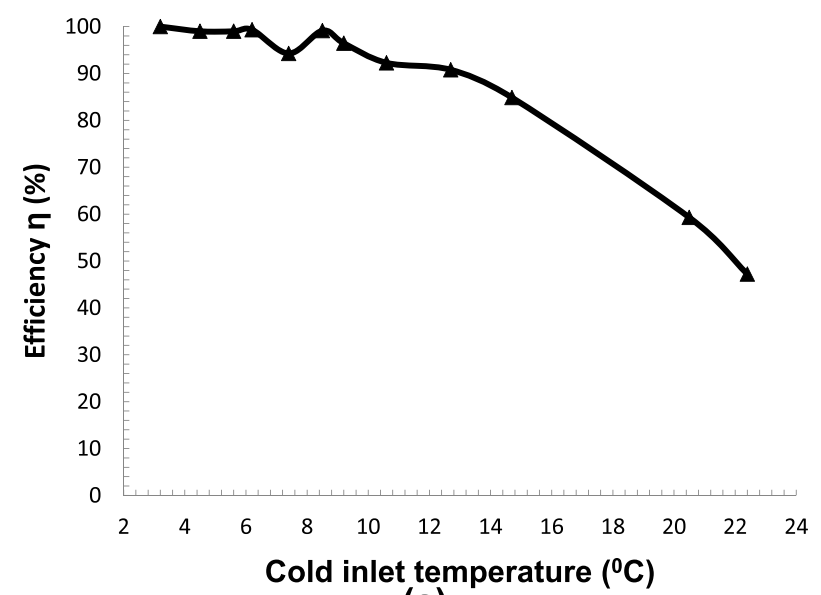

(a)

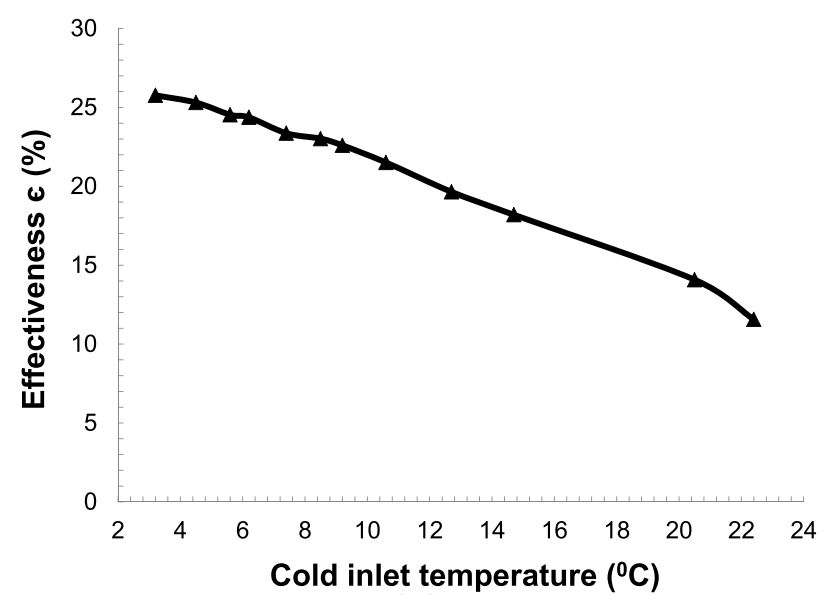

(b)

Fig. 7. Variation of (a) efficiency and (b) effectiveness of the recovery system in function of the cold inlet temperature.

$26 \%$ to $12 \%$. It is striking to note that even if the efficiency and the effectiveness do not represent the same result, indeed the quantitative values are totally different, the evolution of the curves of $\eta$ and $\varepsilon$ are very similar and, above all, in each case, the final value is around $46-47 \%$ of the initial value.

Water flowing from the boiler to the inlet of the drain (inlet of the heat exchanger hot side) loses heat due to loss of flow rate and cooling due to contact with the inner walls of the drain box. The lost heat can be calculated as the difference of energy rate between the outlet of the boiler and the inlet of the drain:

$\dot{Q}_{L}=\dot{m}_{c} C_{p, c} T_{b, o}-\dot{m}_{h} C_{p, h} T_{h, i}$

where $T_{b, o}$ is the temperature of water at the boiler outlet.

The ratio of the lost heat can be calculated as:

$\frac{\dot{Q}_{L}}{\dot{Q}_{b, o}}=\frac{\dot{m}_{c} C_{p, c} T_{b, o}-\dot{m}_{h} C_{p, h} T_{h, i}}{\dot{m}_{c} C_{p, c} T_{b, o}}$

with $\dot{Q}_{b, o}$ the heat at the outlet of the boiler.

Fig. 8 shows the variation of the lost heat $\dot{Q}_{L}$ and the percentage of lost heat $\dot{Q}_{L} / \dot{Q}_{b, o}$ in function of the hot inlet temperature for different cold water flow rates.

It can be shown that losses increase with the boiler outlet temperature. As illustration for a cold water flow rate of $0.058 \mathrm{~kg} / \mathrm{s}$, losses increase from $11 \mathrm{~kW}$ to $12.8 \mathrm{~kW}$ as the boiler outlet temperature increases from $40^{\circ} \mathrm{C}$ to $80^{\circ} \mathrm{C}$. For flow rates of $0.097 \mathrm{~kg} / \mathrm{s}$ and $0.146 \mathrm{~kg} / \mathrm{s}$, losses are respectively from $25.1 \mathrm{~kW}$ to $29.3 \mathrm{~kW}$ and 


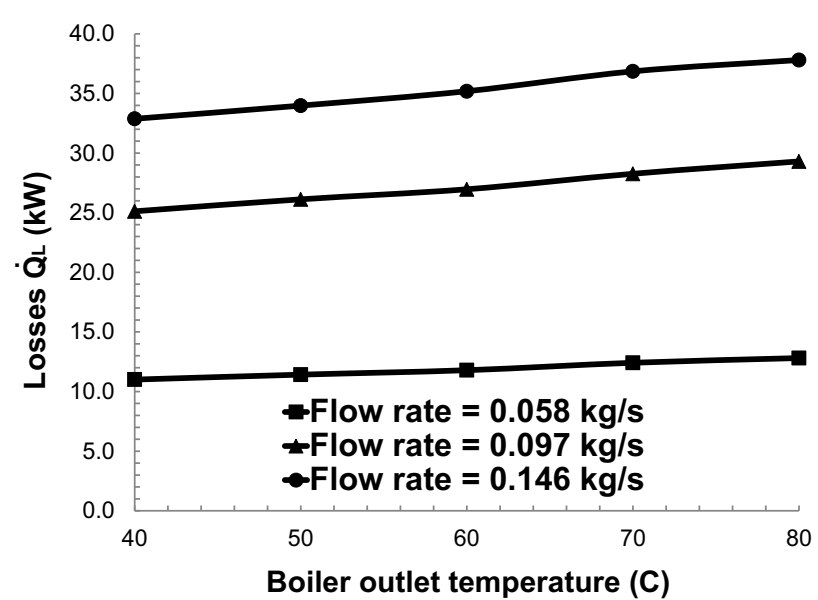

(a)

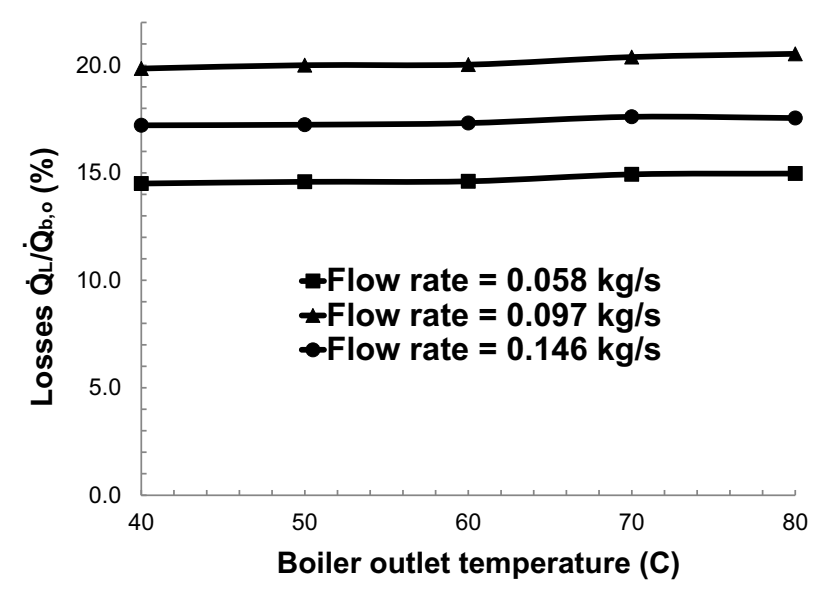

(b)

Fig. 8. Variation of (a) losses and (b) percentage of losses in function of the boiler outlet temperature for different cold flow rates.

from $32.9 \mathrm{~kW}$ to $37.8 \mathrm{~kW}$, for the boiler outlet temperatures varying from $40^{\circ} \mathrm{C}$ to $80^{\circ} \mathrm{C}$.

The percentage of heat lost (Fig. 8b) increases when the flow rate increases from $0.058 \mathrm{~kg} / \mathrm{s}$ to $0.097 \mathrm{~kg} / \mathrm{s}$, then it decreases for higher flow rates. As illustration, the average percentages corresponding to flow rates of $0.058 \mathrm{~kg} / \mathrm{s}, 0.097 \mathrm{~kg} / \mathrm{s}$, and $0.146 \mathrm{~kg} / \mathrm{s}$ are respectively $14.7 \%, 20.2 \%$ and $17.4 \%$.

Fig. 9 shows the variation of the recovered heat in function of the cold flow rate and boiler outlet temperature.

It can be shown that the recovered heat increases with the boiler outlet temperature. As illustration for a cold flow rate of $0.058 \mathrm{~kg} / \mathrm{s}$, the recovered heat increases from $0.05 \mathrm{~kW}$ to $2.42 \mathrm{~kW}$ as the boiler outlet temperature increases from $40^{\circ} \mathrm{C}$ to $80^{\circ} \mathrm{C}$. For flow rates of $0.097 \mathrm{~kg} / \mathrm{s}$ and $0.146 \mathrm{~kg} / \mathrm{s}$, the recovered heat increases respectively from $0.36 \mathrm{~kW}$ to $4.77 \mathrm{~kW}$ and from $0.55 \mathrm{~kW}$ to $5.31 \mathrm{~kW}$.

For a boiler temperature of $50^{\circ} \mathrm{C}$, the recovered heat increases from $0.24 \mathrm{~kW}$ to $1.46 \mathrm{~kW}$ as the cold water flow rate increases from $0.058 \mathrm{~kg} / \mathrm{s}$ to $0.146 \mathrm{~kg} / \mathrm{s}$. For a boiler outlet temperature of $70^{\circ} \mathrm{C}$, the recovered heat increases from $1.58 \mathrm{~kW}$ to $3.91 \mathrm{~kW}$. What is striking from Fig. 9b is the fact that the recovered heat increases highly when the flow rate increases from $0.058 \mathrm{~kg} / \mathrm{s}$ to $0.097 \mathrm{~kg} / \mathrm{s}$, but seems to reach a plateau beyond this value.

The effects of the cold flow rate and boiler outlet temperature on the effectiveness of the exchanger of the recovery system are shown in Fig. 10.

It can be shown that the exchanger effectiveness increases with the boiler outlet temperature. As illustration for a cold flow rate of

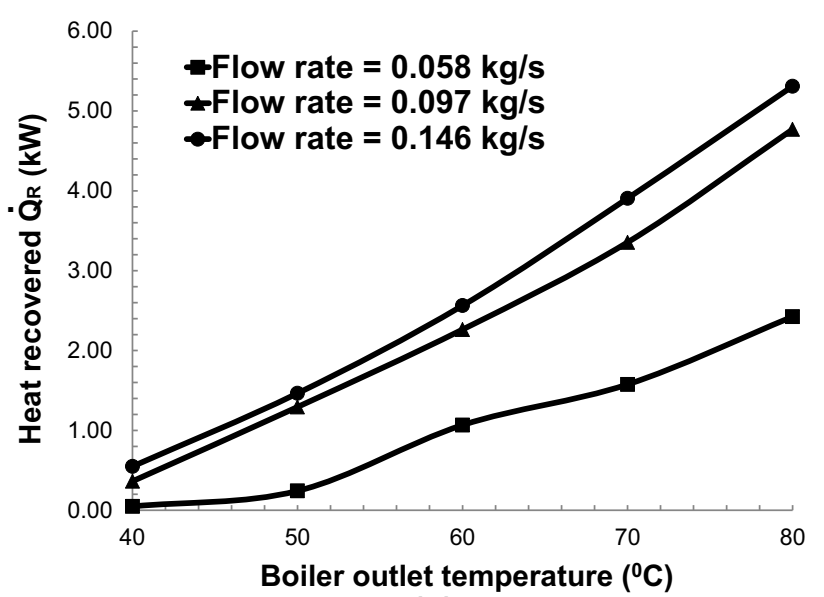

(a)

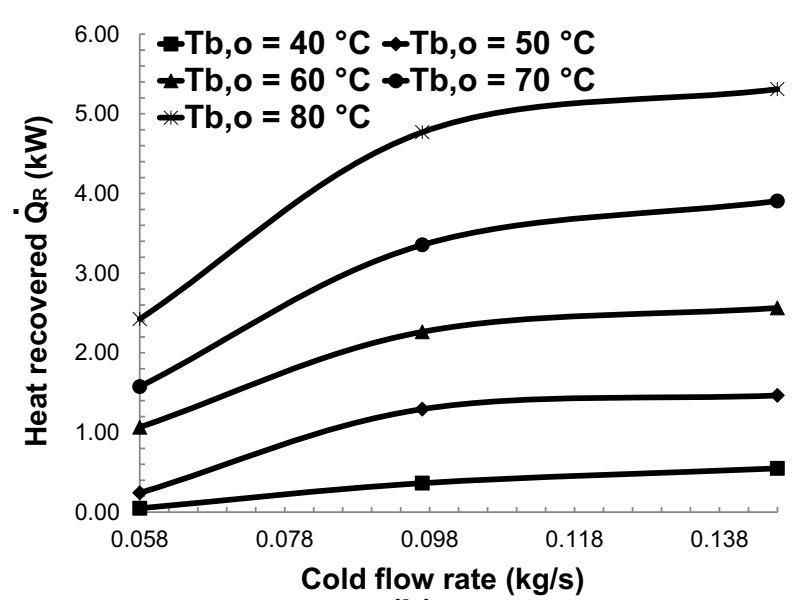

(b)

Fig. 9. Variation of recovered heat (a) in function of the boiler outlet temperature for different cold flow rates and (b) in function of the cold flow rate for different boiler outlet temperatures.

$0.058 \mathrm{~kg} / \mathrm{s}$, the effectiveness increases from $2 \%$ to $23 \%$ as the boiler outlet temperature increases from $40^{\circ} \mathrm{C}$ to $80^{\circ} \mathrm{C}$. For flow rates of $0.097 \mathrm{~kg} / \mathrm{s}$ and $0.146 \mathrm{~kg} / \mathrm{s}$, the effectiveness increases respectively from $9 \%$ to $30 \%$ and from $10 \%$ to $21 \%$.

From Fig. 10b, it can be shown that the effectiveness curves reach maxima in their variations with respect to the cold mass flow rate. To exemplify for a boiler outlet temperature of $60^{\circ} \mathrm{C}$, the effectiveness increases from $16 \%$ to $22 \%$ when the water flow rate increases from $0.058 \mathrm{~kg} / \mathrm{s}$ to $0.097 \mathrm{~kg} / \mathrm{s}$ and then decreases to $16 \%$ when the cold flow rate increases from $0.097 \mathrm{~kg} / \mathrm{s}$ to $0.146 \mathrm{~kg} / \mathrm{s}$.

\section{New calculation procedure}

Based on many features of the results shown in the previous section, a new procedure of calculations that permits to estimate the performance of a recovery system applied to any system of drains and using any heat exchanger type will be presented hereafter. This procedure relies on some scenarios related to the operational mode of a given type of drain. Fig. 11 shows the flow chart of the calculation procedure.

As shown in Fig. 11, the inputs to the calculation procedure are the water flow rate from the supply tank that the drain system (shower chamber, sink, dish washer, washing machine, etc.) requires, the water temperature in the supply tank and the hot temperature related to the system mode (for example water heater temperature in shower application). The calculation procedure will 


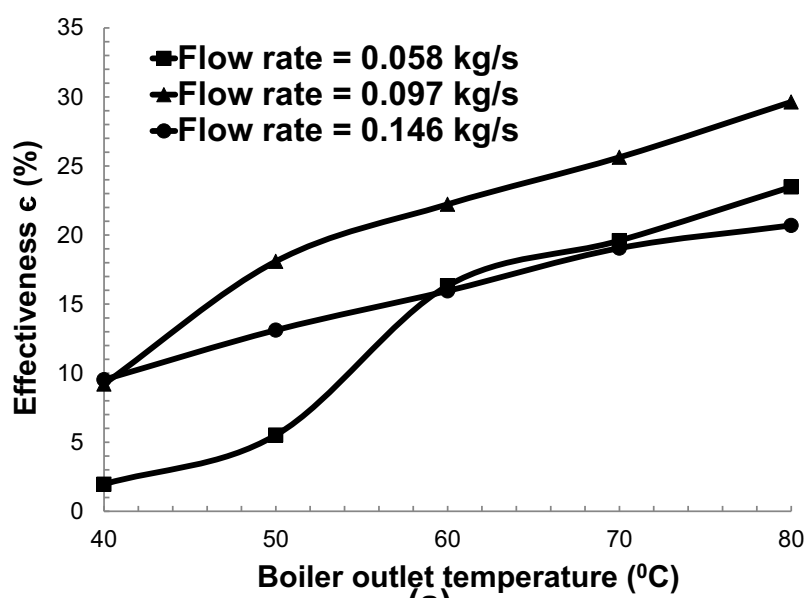

(a)

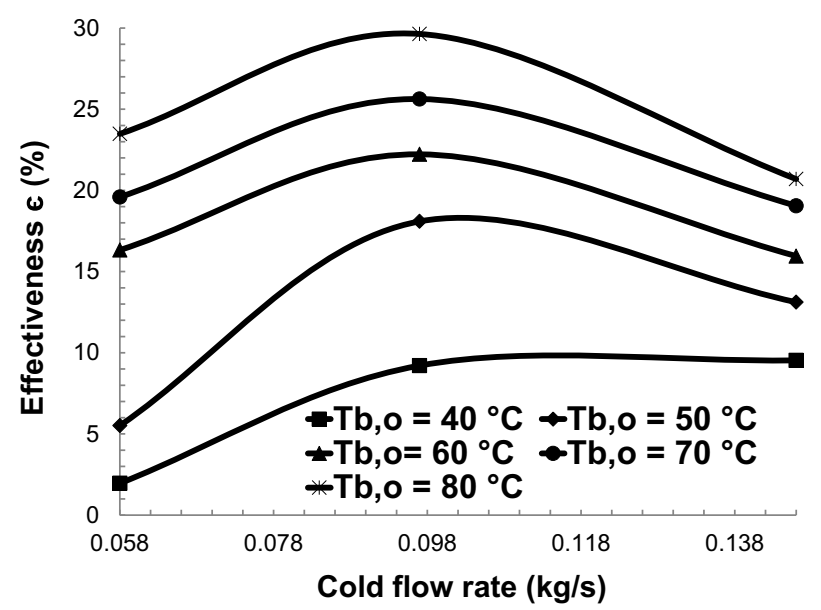

(b)

Fig. 10. Variation of the exchanger effectiveness (a) in function of the boiler outlet temperature for different cold flow rates and (b) in function of the cold flow rate for different boiler outlet temperatures.

estimate several parameters, mainly the recovered heat and the power consumption reduction.

Step 1: From the cold mass flow rate $\dot{m}_{c}$, the hot mass flow rate $\dot{m}_{h}$ can be calculated from the following relation:

$\dot{m}_{h}=R_{1} \dot{m}_{C}$

where $R_{1}$ is a ratio that can be obtained from preliminary measurements for a given drain system and which is function of the operational mode scenario. As illustration from Fig. $4 \mathrm{~b}$, this ratio is around $81 \%$ to $86 \%$.

Step 2: The temperature of hot water at the heat exchanger inlet can be calculated from Eq. (6) rearranged in a different manner as follows:

$T_{h, i}=T_{b, o} \frac{R_{C}}{R_{1}}\left(1-R_{2}\right)$

where $R_{C}=C_{p, c} / C_{p, h}$ is the ratio of the specific heat of the cold water to that of hot water and $R_{2}=\dot{Q}_{L} / \dot{Q}_{b, o}$ the ratio of the rate of energy lost in the drain system to the rate of absolute energy contained in the water at the hot water system of the drain before entering the drain itself.

For the ranges of temperatures of cold and hot water for the most common types of drain, the ratio $R_{C}$ is almost equal to 1 . The ratio $R_{2}$ is also a ratio that can be obtained from preliminary measurements for a given drain system and is function of the operational mode scenario. As illustration from Fig. 7b, this ratio is around $14 \%-21 \%$.
Step 3: From curves of effectiveness and efficiency obtained on the heat exchanger separately from the system and for different cold and hot temperatures and different water flow rates, the effectiveness and efficiency of the heat exchanger under consideration in the recovery system can be obtained. It should be noticed from the experimental analysis performed in the previous section that the effectiveness of the exchanger increases quasi-linearly with the difference in temperature between the inlet hot and cold temperatures and increases exponentially with the flow rate up to a certain value from which it starts to decrease.

Step 4: The rate of heat exchanged in the system which corresponds to the recovered heat can then be calculated as follows:

$\dot{Q}_{R}=\varepsilon \dot{m}_{h} C_{p, h}\left(T_{h, i}-T_{c, i}\right)$

Step 5: The cold water outlet temperature which corresponds to the temperature at the inlet of the heating system of the drain type under consideration can now be calculated:

$T_{c, o}=T_{c, i}+\frac{\dot{Q}_{R}}{\dot{m}_{c} C_{p, c}}$

Step 6: The rate of energy consumed by the heating system of the drain type can now be calculated:

$\dot{Q}_{\text {heating }}=\dot{m}_{c} C_{p, c}\left(T_{b, o}-T_{c, o}\right)$

Step 7: The power consumption reduction (PCR) obtained with the installation of the recovery system can be obtained from:

$P C R=\frac{\dot{Q}_{R}}{\dot{Q}_{R}+\dot{Q}_{\text {Heating }}}$

Step 8: The hot water outlet temperature which corresponds to the temperature of water that will be discharged in the final drain can also be calculated from:

$T_{h, o}=T_{h . i}-\frac{\dot{Q}_{R}}{\eta \dot{m}_{h} C_{p, h}}$

The procedure presented above can be applied to any type of heat recovery system from any type of hot drain system to estimate parameters related to the performance of the recovery concept. This procedure necessitates preliminary measurements on a generic experimental setup such as that presented above in this manuscript to obtain some key parameters and ratios that are used in the different steps of calculations.

\section{Conclusions}

Recovering the waste heat from systems utilized in the daily life is a solution to decrease the domestic energy consumption. In this paper, recovering heat from hot drain water is investigated. Particularly, a generic experimental setup is developed and an appropriate experimental parametric analysis is carried out.

In the parametric analysis, it was particularly found that:

(1) Around $15 \%$ of the water flow rate can be lost, i.e. not available in the system drainage box;

(2) The effectiveness and efficiency of the recovery system decrease with the cold inlet temperature. This decrease can reach $50 \%$ for $20^{\circ} \mathrm{C}$ difference;

(3) Around $15-20 \%$ of the heat of water at the boiler outlet are lost in the system drainage box;

(4) The exchanger effectiveness increases with the boiler outlet temperature. As illustration for a cold flow rate of $0.058 \mathrm{~kg} / \mathrm{s}$, the effectiveness increases from $2 \%$ to $23 \%$ as the boiler outlet temperature increases from $40^{\circ} \mathrm{C}$ to $80^{\circ} \mathrm{C}$.

(5) The effectiveness curves reach maxima in their variations with respect to the cold mass flow rate. To exemplify for a boiler 


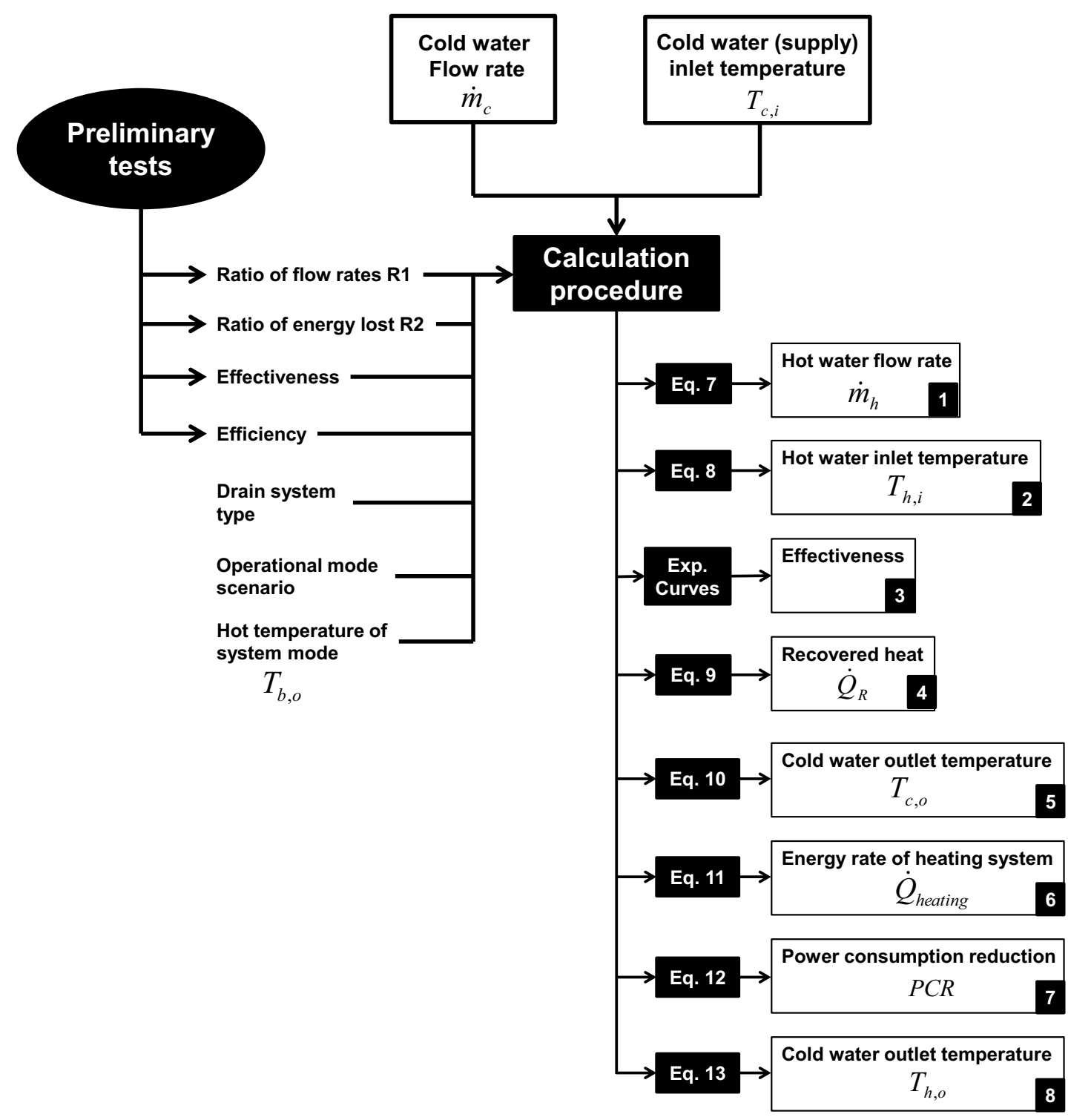

Fig. 11. Flow chart of the calculation procedure.

outlet temperature of $60^{\circ} \mathrm{C}$, the effectiveness increases from $16 \%$ to $22 \%$ when the water flow rate increases from $0.058 \mathrm{~kg} / \mathrm{s}$ to $0.097 \mathrm{~kg} / \mathrm{s}$ and then decreases to $16 \%$ when the cold flow rate increases from $0.097 \mathrm{~kg} / \mathrm{s}$ to $0.146 \mathrm{~kg} / \mathrm{s}$.

Finally and based on the parametric analysis shown, a new design approach consisting of a systematic calculation procedure was presented. It can be utilized as a pre-calculation tool to size drain heat recovery systems or as an optimization technique to enhance an existing system. It was shown that any drain system can be preliminary sized using the new suggested systematic approach based on experimentally determined parameters.

\section{References}

[1] B. Wang, L.D. Cot, L. Adolphe, S. Geoffroy, J. Morchain, Estimation of wind energy over roof of two perpendicular buildings, Energy Build. 88 (2015) 57-67.

[2] L. Lu, K. Sun, Wind power evaluation and utilization over a reference high-rise building in urban area, Energy Build. 68 (2014) 339-350.

[3] E. Shojaeizadeh, F. Veysi, A. Kamandi, Exergy efficiency investigation and optimization of an Al2O3-water nanofluid based flat-plate solar collector, Energy Build. 101 (2015) 12-23.
[4] S. Tamvakidis, V.K. Firfiris, A. Martzopoulou, V.P. Fragos, T.A. Kotsopoulos, Performance evaluation of a hybrid solar heating system for farrowing houses, Energy Build. 97 (2015) 162-174.

[5] N. Naili, M. Hazami, I. Attar, A. Farhat, Assessment of surface geothermal energy for air conditioning in northern Tunisia: direct test and deployment of ground source heat pump system, Energy Build. 111 (2016) 207-217.

[6] A. Kecebas, C. Coskun, Z. Oktay, A. Hepbasli, Comparing advanced exergetic assessments of two geothermal district heating systems for residential buildings, Energy Build. 81 (2014) 141-151.

[7] C.R. Touretzky, M. Baldea, A hierarchical scheduling and control strategy for thermal energy storage systems, Energy Build. 110 (2016) 94-107.

[8] M. Ameri, Z. Besharati, Optimal design and operation of district heating and cooling networks with CCHP systems in a residential complex, Energy Build. 110 (2016) 94-107.

[9] S. Delfani, H. Pasdarshahri, M. Karami, Experimental investigation of heat recovery system for building air conditioning in hot and humid areas, Energy Build. 49 (2012) 62-68.

[10] Y. El Fouih, P. Stabat, P. Rivière, P. Hoang, V. Archambault, Adequacy of air-to-air heat recovery ventilation system applied in low energy buildings, Energy Build. 54 (2012) 29-39.

[11] M.S. Todorovic, J.T. Kim, In search for sustainable globally cost-effective energy efficient building solar system-heat recovery assisted building integrated PV powered heat pump for air-conditioning, water heating and water saving, Energy Build. 85 (2014) 346-355.

[12] J. Jia, W.L. Lee, Applying storage-enhanced heat recovery room air-conditioner (SEHRAC) for domestic water heating in residential buildings in Hong Kong, Energy Build. 78 (2014) 132-142. 
[13] S. Gendebien, S. Bertagnolio, V. Lemort, Investigation on a ventilation heat recovery exchanger: modeling and experimental validation in dry and partially wet conditions, Energy Build. 54 (2012) 29-39.

[14] S. Garimella, Low-grade waste heat recovery for simultaneous chilled and hot water generation, Appl. Therm. Eng. 42 (2012) 191-198.

[15] B. Peris, J. Navarro-Esbri, F. Molès, Bottoming organic Rankine cycle configurations to increase internal combustion engines power output from cooling water waste heat recovery, Appl. Therm. Eng. 61 (2013) 364-371.

[16] J. White, M.C. Gillott, C.J. Wood, D.L. Loveday, K. Vadodaria, Performance evaluation of a mechanically ventilated heat recovery (MVHR) system as part of a series of UK residential energy retrofit measures, Energy Build. 110 (2016) 220-228.

[17] M. Kassai, M.R. Nasr, C.J. Simonson, A developed procedure to predict annual heating energy by heat- and energy-recovery technologies in different climate European countries, Energy Build. 109 (2015) 267-273.

[18] J. Zhang, A.S. Fung, S. Jhingan, Analysis and feasibility study of residential integrated heat and energy recovery ventilator with built-in economizer using an excel spreadsheet program, Energy Build. 75 (2014) 430-438.

[19] J.E. Smith, Recovery and utilisation of heat from domestic waste water, Appl. Energy 1 (1975) 205-214.

[20] S. Kannoh, Heat recovery from warm waste water at dyeing process by absorption heat pump, J. Heat Recovery Syst. 2 (1982) 443-451.

[21] M. De Paepe, E. Theuns, S. Lenaers, J. Van Loon, Heat recovery system for dishwashers, Appl. Therm. Eng. 23 (2003) 743-756

[22] N.C. Baek, U.C. Shin, J.H. Yoon, A study on the design and analysis of a hea pump heating system using wastewater as a heat source, Sol. Energy 78 (2005) 427-440.

[23] L.T. Wong, K.W. Mui, Y. Guan, Shower water heat recovery in high-rise residential buildings of Hong Kong, Appl. Energy 87 (2010) 703-709.
[24] L. Liu, L. Fu, Y. Jiang, Application of an exhaust heat recovery system for domestic hot water, Energy 35 (2010) 1476-1481.

[25] A. McNabola, K. Shields, Efficient drain water heat recovery in horizontal domestic shower drains, Energy Build. 59 (2013) 44-49.

[26] I. Beentjes, R. Manouchehri, M.R. Collins, An investigation of drain-side wetting on the performance of falling film drain water heat recovery systems, Energy Build. 82 (2014) 660-667.

[27] J. Wallin, J. Claesson, Investigating the efficiency of a vertical inline drain water heat recovery heat exchanger in a system boosted with a heat pump, Energy Build. 80 (2014) 7-16.

[28] D. Slys, S. Kordana, Financial analysis of the implementation of a drain water heat recovery unit in residential housing, Energy Build. 71 (2014) 1-11.

[29] S.S. Cipolla, M. Maglionico, Heat recovery from urban wastewater: analysis of the variability of flow rate and temperature, Energy Build. 69 (2014) 122-130.

[30] S.S. Cipolla, M. Maglionico, Heat recovery from urban wastewater: analysis of the variability of flow rate and temperature in the sewer of bologna Italy, Energy Procedia 82 (2014) 660-667.

[31] J. Wallin, J. Claesson, Analyzing the efficiency of a heat pump assisted drain water heat recovery system that uses a vertical inline heat exchanger, Sustain. Energy Technol. Assess. 8 (2014) 109-119.

[32] R. Manouchechri, C.J. Banister, M.R. Collins, Impact of small tilt angles on the performance of falling film drain water heat recovery systems, Energy Build. 102 (2015) 181-186.

[33] R. Amon, M. Maulhardt, T. Wong, D. Kazama, C.W. Simmons, Waste heat and water recovery opportunities in California tomato paste processing, Appl. Therm. Eng. 78 (2015) 525-532.

[34] F.P. Incropera, D.P. DeWitt, Fundamentals of Heat and Mass Transfer, John Wiley and Sons, 2011 